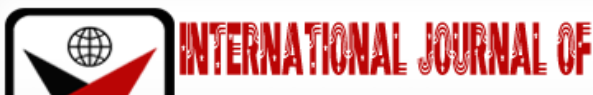

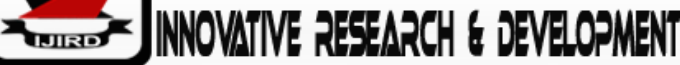

ISSN $2278-0211$ (Online)

\section{Perception of Perioperative Nursing Students towards the Management of Academic Stress in Three Selected Schools in South Western Nigeria}

\author{
Maitanmi Julius Olatade \\ Lecturer, Department of Community/Public Health Nursing, School of Nursing, Babcock University, \\ Nigeria \\ Omotoyinbo Modupe \\ Preoperative/Fertility Nurse, Regix Fertility Clinic, New Bodija, Ibadan, Oyo state, Nigeria \\ Maitanmi Bukola Titilope \\ Senior Nursing Officer, Babcock University Teaching Hospital, Nigeria \\ Leslie Tabitha \\ Lecturer, Department of Community /Public Health Nursing, Babcock University, Nigeria
}

\begin{abstract}
:
Academic stress is the product of a combination of academic related demands that exceed the adaptive resources available to an individual. This study determined the perception of perioperative nursing students towards the management of academic stress in the three selected schools in Southwestern Nigeria. A survey design was adopted which used a purposive sampling technique to select eighty four (84) respondents. A self structured questionnaire was used to obtain information from respondents within 4 weeks. The data collected were processed using SPSS (version 21.0) and analyzed using descriptive and inferential statistics. The results revealed that majority (69.0\%) of the respondents have good perception of academic stress. More than half (58.3\%, 56.0\%, 53.6\%) of the respondents reported that financial difficulties, combining job with studies and excessive workload/assignments are common causes of academic stress respectively while listening to music (95.2\%), talking to friends (79.8\%) and sleep/rest (95.2\%) were the highest reported methods of stress management. It was recommended that Perioperative nursing students should always adopt positive coping mechanisms amidst tight schedules to prevent breaking down.
\end{abstract}

Keywords: Perception, perioperative nursing students, management, academic stress

\section{Introduction}

Humans are currently living in a society that is rapidly changing and requires continual adaptation to new lifestyles, this constant instability necessitate individuals to adapt daily to new situations, resulting in transformation that can lead to stress. It is noted in literature that nursing students are more exposed to stressful events than students studying other courses because they are continually faced with situations of responsibility for the lives and health of patients (Gibbons, Dampster \& Mautray, 2009). The stressful challenges encountered may include insecurity about clinical competence and interpersonal relations with patients, the pressure resulting from the fear of elimination from the training, interacting with dying patients and interpersonal conflicts with other nurses, others are assignment submission, excessive homework, assessment deadlines (Nancy, 2011). Thus stress is somehow inherent in nursing for both staff and students due to the numerous demands required by the profession. Stress is the physical and emotional response humans have to events that threaten them and it is rooted in the primitive fight or flight response wired into human.

The situation that seems to be stressful to the nursing student may cause some negative changes in their psychosocial lives and in their long term physical and mental well-being, they may become irritable, show lack of concentration, decreased academic performance, poor inter-personal relations, insomnia and absenteeism (Dahlin, Joneborg, \& Runeson, 2015). It could result into emotional exhaustion, depersonalization, and decreased personal achievements (Gibbons, 2010). They could also experience deterioration in academic performance which may result into attrition from nursing programs and can lead to shortage of nurses entering clinical career (Watson, Deary, Thompson, \& Li, 2008). Since nursing student experience diverse 
types of stresses and the consequences, the ability to cope with stress is essential for them to succeed and adopting appropriate coping strategy to manage it is very important for counteracting the negative effects of stress. Studies have shown that when coping with stress is successful, adaptation takes place and promotes health, psychological well-being and social functioning (Soares \& Oliveira, 2013). Coping strategies protects an individual by reducing the threat and frustration. It is done by eliminating or modifying conditions giving rise to the problems and also by controlling the meaning of the experience in the manner, which neutralizes its problematic character (Asuzu, 2009). Effective coping strategies help students to perform markedly better in regards to their studies; coping strategies also aid in relieving students' stress (Khater, Akhu-Zaheya \& Shaban, 2014).

Coping with stress for nursing students is a dynamic and ongoing process, aimed at survival, growth, maintenance of the individuals integrity and by using various coping strategies whether healthy or unhealthy, the imbalance and disequilibrium is restored (Nancy, 2011) Students cannot avoid stress but their ability to cope with these stressors and their attitude towards managing it is important in achieving success in their academic performance. This study will therefore examine the common academic stressors encountered by perioperative nursing students and their perception towards the management in the three selected perioperative nursing schools in Southwest Nigeria.

\subsection{Statement of the Problem}

Perioperative nursing is a highly specialized demanding nursing specialty requiring knowledge and skills not included in baccalaureate nursing programs, which exposes students to different forms of stress mostly academic stress. Perioperative nursing encompasses care of the patient before, during, and after surgery. Specialized knowledge, skills, and competencies are required to assume the professional perioperative practice role. The operating theatre department is a very delicate and vital unit of the hospital which is the major training ground for perioperative nursing students and requires student to be highly intelligent, skillful and physically fit to be able to withstand the numerous rigors peculiar to perioperative nursing such as standing for long hours in the operating room, ability to anticipate patient and surgeon need and effective management skills among others. It has been observed that this predisposes the perioperative nursing student to a higher level of stress compared to other nursing specialties. Some of the perceived effects of these stressful situations to the perioperative nursing students are negative changes in psychosocial lives, physical and mental wellbeing, lack of concentration, decreased academic performance, poor interpersonal relationship, insomnia and absenteeism (Sharif, 2015). Other studies have been extensively conducted on the topic in developed countries but there is dearth of information on academic stress and the adopted coping strategies among nursing students in Nigeria. So managing academic stress effectively and seeking coping strategy in an appropriate way is very important for preventing the negative effects of stress. Therefore, this study appraised the level of stress, identify common stressors, and examine ways of managing academic stress among enrolled perioperative nursing students in the three selected perioperative nursing schools in Southwestern Nigeria.

\subsection{Objectives of the Study}

- To assess the perception of perioperative nursing students towards academic stress.

- To enumerate perceived common causes of academic stress among perioperative nursing students.

- To identify the methods of stress management adopted by perioperative nursing students.

\subsection{Significance of the Study}

This result of this research provided essential and useful information about perception and management of academic stress among perioperative nursing students and the entire nursing students at various levels of study. The study identified different coping strategies utilized by perioperative nursing students to effectively manage their academic stress and it also improved the knowledge of the researcher on academic stress and research generally. This work is also expected to stimulate further researchers to research into the topic which might eventually lead to other discoveries in managing academic stress among perioperative nursing students. Finally the outcome of this study provided information for other researchers in relation to academic stress management and also contributed to the existing body of knowledge in nursing.

\subsection{Research Hypotheses}

- $\mathrm{H}_{0} 1$ : There is no significant association between the student's age and the perception towards academic stress

- $\mathrm{H}_{0} 2$ : There is no significant association between gender and stress perception among perioperative nursing students.

- $\mathrm{H}_{0} 3$ : There is no significant association between student's marital status and the adopted ways of managing academic stress.

\subsection{Scope of the Study}

The study was carried out among the perioperative nursing students in all perioperative nursing schools in Southwestern Nigeria which are: Perioperative Nursing School, University College Hospital, Ibadan, Oyo state (PONS, UCH), Perioperative Nursing School, Obafemi Awolowo University Teaching Hospital Complex, Ile-ife, Osun state (PONS, OAUTHC) and Perioperative Nursing School, Lagos University Teaching Hospital, Idi- Araba, Lagos State (PONS, LUTH). 


\section{Methodology}

\subsection{Research Design}

A survey design of descriptive research was used for this study with the main objective of evaluating the perception of perioperative nursing students towards management of academic stress.

\subsection{Research Setting}

The research settings for this study was all the Perioperative Nursing Schools in South West Nigeria which are Perioperative Nursing School, UCH, Ibadan, Perioperative Nursing School, OAUTHC, Ile-Ife and Perioperative Nursing School, LUTH, Idi-Araba, Lagos.

\subsection{Target Population} schools.

The target population of this study were 2016/2017 sets of Perioperative Nursing students in the three selected

\subsection{Sample and Sampling Technique}

The researcher used purposive sampling technique to choose the 84 respondents which are all the students of the three selected schools for easy generalization of the findings of the study.

\subsection{Instrumentation}

The researcher used a self structured questionnaire to elicit information from the respondents which helped in achieving the objectives of the study. The questionnaire consists of 4 sections.

\subsection{Method of Data Collection}

The researcher introduced herself to the respondents, the purpose of the study was explained to them, and this was followed by the distribution of the questionnaires after they have given their consent. The copies of the questionnaire were distributed by the researcher in the classes where the students were present and collected immediately upon completion to avoid loss of tool. However, the whole process took the researcher two weeks duration due to having to travel to different schools.

\subsection{Method of Data Analysis}

After data collection, the data entry was done which involved the conversion of raw source material to a useable data file in form of data analysis. The variables were defined and coded using the statistical package for social sciences (SPSS 21.0). The data were subjected to descriptive (frequency tables, percentages and proportions, bar charts, pie charts, mean and standard deviations) and inferential (chi-square) statistical treatment. Descriptive statistics was employed to describe characteristics of the study participants and the study variables, while the chi-square test was used to investigate associations between categorical variables. The level of statistical significance was set at 0.05 or $5 \%$ for all analysis in this study.

\subsection{Ethical Considerations}

Approval was taken from the administrative offices of all the selected Institutions for data collection. Permission of the appropriate authorities of the schools and personal consents were sought before final distribution of the questionnaires.

\section{Results of the Study}

\begin{tabular}{|c|c|c|c|c|c|c|c|c|}
\hline Common Perceptions (n=84) & \multicolumn{2}{|c|}{ SA } & \multicolumn{2}{|c|}{ A } & \multicolumn{2}{|c|}{ D } & \multicolumn{2}{c|}{ SD } \\
\hline Academic Stress is a feeling of discomfort & N & $\%$ & N & $\%$ & N & $\%$ & N & $\%$ \\
\hline Academic Stress is unavoidable in the training process & 39 & 46.4 & 36 & 42.9 & 8 & 9.5 & 1 & 1.2 \\
\hline Academic Stress can be positive or negative & 42 & 50.0 & 41 & 48.8 & 3 & 3.6 & 0 & 0.0 \\
\hline Positive stress is needed for successful performance & 43 & 51.2 & 34 & 40.5 & 2 & 2.4 & 5 & 6.0 \\
\hline Academic stress is an example of positive stress & 49 & 58.3 & 26 & 31.0 & 5 & 6.0 & 4 & 4.8 \\
\hline
\end{tabular}

Table 1: Perception of Perioperative Nursing Students towards Academic Stress 


\begin{tabular}{|c|c|c|}
\hline Scores & Frequency & Percentage (\%) \\
\hline Good perception & 58 & 69.0 \\
\hline Poor perception & 26 & 30.9 \\
\hline Total & 84 & 100.0 \\
\hline
\end{tabular}

Table 2: Summary of Respondents' Perception of Academic Stress

From table 2, it was revealed that 58(69.0\%) of the respondents have good perception of academic stress.

Note: The composite score of perception of academic stress was computed by assigning a score of $(4=\mathrm{SA} ; 3=\mathrm{A} ; 2=\mathrm{D}$; and $1=\mathrm{SD}$ ).The scores were summed up and maximum obtainable score for perception was 20 and this was converted into percentage by dividing their respective scores by 20 and multiplying by 100 . The perception percentage (\%) score was categorized into 2:

Good perception was scored as $60 \%$ and above.Poor perception was scored as below $60 \%$. More than three-quarter of the respondents reported that academic stress is a feeling of discomfort; and this agrees with Edwards (2010) who examined academic stress among nursing students in Philippines, the result of the study indicated that majority of the students perceived stress as a feeling of discomfort while just a few disagreed with it. In addition, Bernstein (2008), who viewed stress as a negative emotional, cognitive, behavioral and physiological process that occurs as a person tries to adjust to or deal with stressors. High proportion of the respondents reported that positive stress is needed for successful performance, and this could be attributed to the fact that the acceptable levels of stress help to improve the individuals' performance whilst excessive amounts of stress can lead to a decreased performance (Lazarus \& Folkman, 2014).

The study also revealed that majority of the respondents reported that academic stress is unavoidable in the training process. Also, $96.4 \%$ of the respondents reported that academic stress can be positive or negative. Majority of the respondents reported that positive stress is needed for successful performance; and $89.3 \%$ of the respondents reported that academic stress is an example of positive stress. This agrees with a study conducted by Goff (2011), where he evaluated the perception of academic stress in baccalaureate nursing students in southeastern university in the united states, the results showed that $80 \%$ of respondents believed that academic stress is unavoidable in the training process, while minority do not agree with the idea, the study further showed that $60 \%$ agreed that academic stress can either be positive or negative and only a minority agreed that positive stress is needed for successful performance.

It was also noted in this study that $96.4 \%$ of the respondents claimed that academic stress can be positive or negative; and this is in agreement with Stevenson \& Harper (2016), who highlighted that academic stress in academic institutions can have both positive and negative consequences if not well managed.

This study also reflected that majority of the student have good perception of academic stress; and this could be attributed to the fact that there are situations that can affect most of the people, yet everyone seems to interpreting and assessing each situation according to its own subjective criteria and addresses it by his own unique way (Richardson, Poole \& Zook, 2008).

\begin{tabular}{|c|c|c|c|c|c|c|c|c|}
\hline Perceived Causes (n=84) & \multicolumn{2}{|c|}{ SA } & \multicolumn{2}{|c|}{$\mathbf{A}$} & \multicolumn{2}{c|}{$\mathbf{D}$} & \multicolumn{2}{c|}{ SD } \\
\hline Clinical experiences & $\mathbf{N}$ & $\mathbf{\%}$ & $\mathbf{N}$ & $\mathbf{\%}$ & $\mathbf{N}$ & $\mathbf{\%}$ & $\mathbf{N}$ & $\mathbf{\%}$ \\
\hline Parent expectations & 37 & 44.0 & 40 & 47.6 & 4 & 4.8 & 3 & 3.6 \\
\hline Decline in personal health & 21 & 25.0 & 39 & 46.4 & 16 & 19.0 & 8 & 9.5 \\
\hline Financial difficulties & 34 & 40.5 & 46 & 54.8 & 2 & 2.4 & 2 & 2.4 \\
\hline Competition with fellow students & 49 & 58.3 & 32 & 38.1 & 2 & 2.4 & 1 & 1.2 \\
\hline Combining job with studies & 25 & 29.8 & 36 & 42.9 & 15 & 17.9 & 8 & 9.5 \\
\hline Less vacations/break & 47 & 56.0 & 31 & 36.9 & 3 & 3.6 & 3 & 3.6 \\
\hline Inability to balance theory with practical & 41 & 48.8 & 34 & 40.5 & 3 & 3.6 & 6 & 7.1 \\
\hline Poor academic performance & 25 & 29.8 & 44 & 52.4 & 7 & 8.3 & 8 & 9.5 \\
\hline Excessive workload/assignments & 40 & 47.6 & 32 & 38.1 & 9 & 10.7 & 3 & 3.6 \\
\hline Missing lectures & 45 & 53.6 & 34 & 40.5 & 1 & 1.2 & 4 & 4.8 \\
\hline Personal pre-occupations & 21 & 25.0 & 36 & 42.9 & 16 & 19.0 & 11 & 13.1 \\
\hline Preparing for examinations & 27 & 32.1 & 43 & 51.2 & 5 & 6.0 & 9 & 10.7 \\
\hline Change in living environment & 41 & 48.8 & 36 & 42.9 & 3 & 3.6 & 4 & 4.8 \\
\hline Inadequate provision of safety and security & 28 & 26.2 & 54 & 64.3 & 6 & 7.1 & 2 & 2.4 \\
\hline Lack of recreational facilities & 26 & 31.0 & 40 & 47.6 & 11 & 13.1 & 5 & 6.0 \\
\hline Inadequate supply of electricity & 32 & 38.1 & 38 & 45.8 & 8 & 9.5 & 9 & 10.7 \\
\hline Uncomfortable classroom & 35 & 41.7 & 38 & 45.2 & 7 & 8.3 & 4 & 4.8 \\
\hline
\end{tabular}

Table 3: Perceived Common Causes of Academic Stress among Perioperative Nursing Students 
About $72.6 \%$ and $96.4 \%$ of the respondents claimed that competition with fellow students and financial difficulties respectively are common causes of academic stress. This agrees with Bernstein et al (2008) who observed that social competition, economic difficulties, interpersonal relationships, business pressures, and, rapid changes in social and moral values, immigration, relocation, removal, and hospitalization are some examples of stressful stimuli.

The study also revealed that majority of the respondents reported that parental expectations, decline in personal health and personal preoccupations respectively are common causes of academic stress; and this is in line with Bernstein et al (2008) who highlighted some examples of stressful stimulus to include illness, surgery, pain, exposure to excessive cold or heat, intense muscle activity, sensory overload (e.g. noise pollution), accident. Also, some common academic stressors can be classified into intrapersonal, and this include parent's expectations, decline in personal health, personal preoccupations, change in eating pattern, engagement/marriage, homesickness in hostel, change in sleeping pattern, new responsibilities of life, death of significant one, financial problems, and change in religious beliefs (Bernstein et al; 2008). In addition, Gupta and Khan (2009) highlighted that academic stress refers to the unpleasant psychological situations that occur due to the educational expectations from parents, teachers, peers and family members, pressure of parents for academic achievement, present educational and examination system, burden of home work etc.

It was noted in the study that majority of the respondents reported that less vacations/break, inability to balance theory with practical, excessive workload/assignments, poor academic performance and missing lectures respectively are common causes of academic stress. This supports Bernstein et al (2008) who observed some common academic stressors to include academic factors such as less vacations/breaks, inability to balance study and leisure time, over burden with study, inability to concentrate on study, poor satisfaction with class room performance, getting lower grade than anticipation,

inability to enjoy my study, class presentations, difficulty to understand language used by teachers while teaching, poor interest in studies, serious argument with teachers, practical work, missing too many classes. Also, Brown (2009) viewed the sources of stress to include excessive homework, unclear assignments, and uncomfortable classrooms.

The study also reflected that majority of the respondents also reported that lack of recreational facilities, inadequate supply of electricity, inadequate provision of safety and security and uncomfortable classroom are common causes of academic stress respectively. This is in agreement with Bernstein et al (2008) whose findings identified the common environmental academic stressors to include change in living environment, inadequate telephone facilities, inadequate provision of safety and security, inadequate facility of canteen, lack of recreational facilities, lack of laundry facilities, absence of calm and quiet environment, extreme climate factors, inadequate supply of electricity and inadequate water supply. Similarly, Hart and Rotem (2011) identified stressful events among 100 first-year Nepalese nursing students, the inadequate provision of safety and security was labeled as top academic stress inducing factor by $95 \%$ subjects whereas $89 \%$ of subjects attributed academic stress to less vacation and breaks. Also, the lack of recreational activities and poor laundry services was considered stressful by $84 \%$ subjects. For $78 \%$ of subjects the absence of calm \& quiet environment and extremes of climate were stress inducing factors. However inadequate water supply (19\%) and inadequate supply of electricity (12\%) had minimum contribution towards stress inducing factors.

\begin{tabular}{|c|c|c|c|c|}
\hline Coping Mechanism (n=84) & \multicolumn{2}{|c|}{ Yes } & \multicolumn{2}{c|}{ No } \\
\hline & $\mathbf{N}$ & $\mathbf{\%}$ & $\mathbf{N}$ & $\mathbf{\%}$ \\
\hline Listening to music & 80 & 95.2 & 4 & 4.8 \\
\hline Talking to friends & 67 & 79.8 & 17 & 20.2 \\
\hline Going for exercise & 64 & 76.2 & 20 & 23.8 \\
\hline Denial of the stressor & 38 & 45.2 & 46 & 54.8 \\
\hline Avoidance of the stressor & 48 & 57.1 & 36 & 42.9 \\
\hline Sleep and rest & 80 & 95.2 & 4 & 4.8 \\
\hline Smoking & 7 & 8.3 & 77 & 91.7 \\
\hline Alcohol consumption & 5 & 6.0 & 79 & 94.0 \\
\hline Apportioning blames & 8 & 9.5 & 76 & 90.5 \\
\hline Social media & 58 & 69.0 & 26 & 31.0 \\
\hline Seeking professional help & 69 & 82.1 & 15 & 17.9 \\
\hline Seeking spiritual help & 58 & 69.0 & 26 & 31.0 \\
\hline
\end{tabular}

Table 4: Methods of Stress Management/Coping Mechanism among

Perioperative Nursing Students 


\begin{tabular}{|c|c|c|}
\hline Scores & Frequency & Percentage (\%) \\
\hline Good methods of stress management & 59 & 70.2 \\
\hline Poor methods of stress management & 25 & 29.8 \\
\hline Total & 84 & 100.0 \\
\hline
\end{tabular}

Table 5: Summary of Respondents' Methods of Stress Management

From table 5, it was revealed that 59(70.2\%) of the respondents have good methods of stress management.

Note: The composite score of methods of stress management was computed by assigning a score of 1 to correct answers and 0 to wrong answers. The scores were summed up and maximum obtainable score for methods of stress management was 12; and this was dichotomized at cut-off point of 9 (Mean methods of stress management $=9.4$ ). Respondents' with a score of 9 and above was categorized as good methods of stress management and a score less than 9 as poor methods of stress management.

$79.8 \%$ of the respondents reported that talking to friends is method of stress management. This is in line with Derek (2011) who highlighted that social support is one of the best moderators of stress. It is used as a way of coping with stress by discussing stressful situations with colleagues, peers, family members, friends and seeking spiritual support. The social support gives good beneficial effect to reduce stress. The beneficial effects of work-based support are much greater because the recipient feels that people can more readily appreciate the problems.

Majority of the respondents respectively reported that listening to music and going for exercise are methods of stress management. Also, more than three-quarter of the respondents reported that sleep and rest are method of stress management and this supports Derek (2011) whose findings observed that relaxation technique can help cope with stress and is likely to be beneficial. The person could force himself or herself to take a holiday or even be ordered to do so. In addition, there are a number of easily taught relaxation techniques that can be used such as listening to music, breathing exercises, muscle relaxation and meditation. The meditation technique is more beneficial to physical and mental states. Similarly, regular physical exercise such as jogging, walking and workout in fitness centre are helpful. They not only improve blood circulation but also lower blood pressure, muscle tension and cholesterol levels. It has more subtle effects. The feeling of general wellbeing can help to combat some of the symptoms of stress when people are relaxed; they tend to sleep more soundly. It provides periods of intense relaxation and enables a person to marshal reserves of energy.

The study also revealed that $45.2 \%, 57.1 \%$ and $95.2 \%$ of the respondents reported that denial of the stressor, avoidance of the stressor and sleep and rest are method of stress management. However, only minority of the respondents reported that smoking, alcohol consumption and apportioning blames respectively are methods of stress management. This agrees with Freeburn and Sinclair (2009) who evaluated the coping mechanism of stress utilized by nursing students, and participants reported utilizing negative coping mechanisms including denial, avoidance, apportioning blames, smoking and increased alcohol consumption.

\subsection{Testing of Hypotheses}

- $\mathrm{H}_{0}$ 1: There is no significant association between students' age and the perception towards management of academic stress.

\begin{tabular}{|l|l|l|l|l|}
\hline \multirow{2}{*}{$\begin{array}{c}\text { Respondents' Age } \\
\text { (Years) }\end{array}$} & \multicolumn{2}{|c|}{ Respondents' Perception towards Management of } & \multirow{2}{*}{ Total } \\
\cline { 2 - 4 } & Good perception & Fair perception & Poor perception & \\
\hline $21-25$ & $4(10.0 \%)$ & $13(32.5 \%)$ & $23(57.5 \%)$ & $40(100 \%)$ \\
\hline $26-30$ & $2(12.5 \%)$ & $1(6.2 \%)$ & $13(81.2 \%)$ & $16(100 \%)$ \\
\hline $31-35$ & $2(12.5 \%)$ & $2(12.5 \%)$ & $12(75.0 \%)$ & $16(100 \%)$ \\
\hline$\geq 36$ & $1(8.3 \%)$ & $1(8.3 \%)$ & $10(83.3 \%)$ & $12(100 \%)$ \\
\hline Total & $9(10.7 \%)$ & $17(20.2 \%)$ & $58(69.0 \%)$ & $84(100 \%)$ \\
\hline
\end{tabular}

Table 6: Cross Tabulation of Age and the Perception towards Management of Academic Stress

$$
X^{2}=7.564, \quad D f=6, \quad P \text {-Value }=0.272 \quad \text { Remark: } P>0.05
$$

Table 6 shows that there is no significant association between students' age and the perception towards management of academic stress $\left(\chi^{2}=7.564, \mathrm{df}=6, \mathrm{p}>0.05\right)$.

- $\mathrm{H}_{0} 2$ : There is no significant association between gender and stress perception among perioperative nursing students. 


\begin{tabular}{|l|l|l|l|c|}
\hline \multirow{2}{*}{ Sex } & \multicolumn{3}{c|}{ Respondents' Perception towards Management of } & \multirow{2}{*}{ Total } \\
\cline { 2 - 4 } & Good perception & Fair perception & Poor perception & \\
\hline Male & $3(12.0 \%)$ & $2(8.0 \%)$ & $20(80.0 \%)$ & $25(100 \%)$ \\
\hline Female & $6(10.2 \%)$ & $15(25.4 \%)$ & $38(64.4 \%)$ & $59(100 \%)$ \\
\hline Total & $9(10.7 \%)$ & $17(20.2 \%)$ & $58(69.0 \%)$ & $84(100 \%)$ \\
\hline
\end{tabular}

Table 7: Cross Tabulation of Gender and Stress Perception among Perioperative Nursing Students

$$
X^{2}=3.307, \quad D f=2, \quad P \text {-Value }=0.191 \quad \text { Remark: } P>0.05
$$

Table 7 shows that there is no significant association between gender and stress perception among perioperative nursing students $\left(\chi^{2}=3.307, \mathrm{df}=2, \mathrm{p}>0.05\right)$.

- $\mathrm{H}_{0} 3$ : There is no significant relationship between students' marital status and the adopted ways of managing academic stress.

\begin{tabular}{|c|c|c|c|}
\hline \multirow{2}{*}{ Marital Status } & \multicolumn{2}{|c|}{ Respondents' Adopted Ways of Managing Academic Stress } & \multirow{2}{*}{ Total } \\
\cline { 2 - 3 } & $\begin{array}{c}\text { Good ways of managing } \\
\text { academic stress }\end{array}$ & $\begin{array}{c}\text { Poor ways of managing academic } \\
\text { stress }\end{array}$ & \\
\hline Single & $36(69.2 \%)$ & $16(30.8 \%)$ & $52(100 \%)$ \\
\hline Married & $20(69.0 \%)$ & $9(31.0 \%)$ & $29(100 \%)$ \\
\hline Divorced & $3(100.0 \%)$ & $0(0.0 \%)$ & $3(100 \%)$ \\
\hline Total & $59(70.2 \%)$ & $25(29.8 \%)$ & $84(100 \%)$ \\
\hline
\end{tabular}

Table 8: Cross Tabulation of Students' Marital Status and the Adopted Ways of Managing Academic Stress

$$
X^{2}=1.319, \quad D f=2, \quad P \text {-Value }=0.517 \quad \text { Remark: } P>0.05
$$

Table 8 shows that there is no significant association between students' marital status and the adopted ways of managing academic stress $\left(\chi^{2}=1.319, \mathrm{df}=2, \mathrm{p}>0.05\right)$.

\subsection{Implication of findings for Nursing}

The findings from this study has shown that perioperative nursing students experience academic stress and they see it as a feeling of discomfort, though they have good management strategies to cope with academic stress, proper methods should still be reinforced as few of them still lack knowledge on how to effectively manage academic stress.

\section{Conclusion}

This study has been able to determine the perception of perioperative nursing students towards the management of academic stress in the three selected schools in Southwestern Nigeria. Academic stress is unavoidable in the perioperative training process. But it could be managed to reduce its negative effect on the Perioperative nursing students. Lack of recreational facilities and excessive workload/assignments are some of the causes of academic stress.

\section{Recommendations}

Based on the findings of this study, the following recommendations were made:

- The perioperative nursing schools should organize a general forum for all the students to address any issue contributing to academic stress.

- Perioperative nursing students should not be over worked or stressed as this result in lack of concentration which may cause poor performance.

- The school management should provide recreational facility to her students so as to provide means of relaxation.

- Adequate rest and excise regularly should be encouraged for all Perioperative nursing students.

\subsection{Suggestions for further Studies}

Based on the findings of this study, the researcher is suggesting that similar research on the perception of students towards the management of academic stress should be carried out in other tertiary institutions. The scope of the study can be enlarged for more generalization.

\section{References}

i. Agolla, J.E., and Ongori, H. (2009). An Assessment of Academic Stress among Undergraduate Students: The Case of University of Botswana. Educational Research and Review, 4(2), 63-70.

ii. American College Health Association. (2009). National college health assessment spring. Journal of American College Health, 5(1), 477-488. 
iii. Ang, R.P., and Huan, V.S. (2016). Academic Expectations Stress Inventory (AESI): Educational and Psychological Measurement, 66 (1), 522-539.

iv. Araas, T. (2008). Associations of mindfulness, perceived stress, and health behaviors in college freshmen. Dissertation Abstracts International: Section A. Humanities and Social Sciences. 69 (2), 521.

v. Asuzu, C.C. (2009). Shift Duty and Stress Coping Strategies among Nurses in the University College Hospital, Ibadan. 11(3), 153-159.

vi. Awino, J.O., and Agolla, J.E. (2008). A quest for sustainable quality assurance measurement for universities: case study of the University of Botswana, 3 (6), 213-218.

vii. Basavanthappa, B. T. (2014). Fundamentals of Nursing; (10 th ed.). New Delhi: Jaypee brothers medical publishers.

viii. Beck, D.L., and Srivastava, R. (2015). Perceived level and sources of stress in baccalaureate nursing students. Journal Nurse Education, 30(3), 127-133

ix. Berman, A., and Snyder, S. (2012). A book of Kozier \& Erb`s Fundamental of nursing concept process and practice; (9 $9^{\text {th }}$ ed.). New Jersey: Pearson Prentice Hall.

x. Bernstein, D.A., Penner, L.A., Stewart, A.C., and Roy, E.J. (2008). Psychology (8 ${ }^{\text {th }}$ ed.). New York: Houghton Mifflin Company Boston.

xi. Brown, D.R., Winer, B.J., and Michels, K.M. (2011). Statistical principals in experiment.

xii. Chan, C. L., So, W. W., and Fong, D. T. (2009). Hong Kong baccalaureate nursing students' stress and their coping strategies in clinical practice. Journal of Professional Nursing, 25(5), 307-313.

xiii. Chang, K., and Lu, L. (2007). Characteristics of organisational culture, stressors and wellbeing: The case of Taiwanese organizations, 22 (6), 549-568.

xiv. Cohen, J., and Single, L.E. (2011). A Global measure of perceived stress. Journal of Health and Social Behavior, Vol 24(4), 385-396.

xv. Derek, R. (2011). Sources of Stress and Coping Behaviors in Clinical Practice among Baccalaureate Nursing Students. International Journal of Humanities and Social Science, 4 (1).

xvi. Dua, J.K. (2014). Job Stressors and Their Effects on Physical Health, Emotional Health, and Job Satisfaction in a University, 4(1), 59-78.

xvii. Dunser, M., and Hasibeder, W. (2009). Sympathetic overstimulation during critical illness: adverse effects of adrenergic stress. Journal of Intensive Care Medicine, 24(5), 293-316.

xviii. Edwards, D., Burnard, P., Bennett, K., and Hebden, U. (2010). A longitudinal study of stress and self-esteem in student nurses. Nurse Education Today, 30(1), 78-84.

xix. Erkutlu, H.V., and Chafra, J. (2016). Relationship between leadership power bases and job stress of subordinates: example from boutique hotels, 29(5), 285-297.

xx. Fairbrother, K., and Warn, J. (2013). Workplace Dimensions, Stress and Job Satisfaction, 18(1), 8-21.

xxi. Fawcett, J. (2013). The Roy Adaptation Model, 36(2), 67-73.

xxii. Forbes, M. O., and Hickey, M. T. (2009). Curriculum reform in baccalaureate nursing education: review of literature. International Journal of Nursing Education Scholarship, 6(1), 1-16.

xxiii. Forshee, B. A., \& McCance, K. L. (2008). Stress and disease. Understanding pathophysiology (4th ed.).

xxiv. Freeburn, M., \& Sinclair, M. (2009). Mental health nursing students" experience of stress: burdened by a heavy load. Journal of Psychiatric \& Mental Health Nursing, 16(4), 335-342.

xxv. Gibbons, C. (2010). Stress, coping and burn-out in nursing students. International Journal of Nursing Studies, 47(1), 1299-1309.

xxvi. Gibbons, C., Dempster, M., \& Moutray, M. (2009). Surveying nursing students on their sources of stress: a validation study. Nurse Education Today, 29(8), 867-872.

xxvii. Goff, A. (2011). Stressors, academic performance, and learned resourcefulness in baccalaureate nursing students. International Journal of Nursing Education Scholarship, 8(1), 1-20.

xxviii. Goodman, E.D. (2013). How to handle the stress of being a student.

xxix. Gupta, K., and Khan, B.N. (2007). Anxiety level as a factor in concept formation. $\quad$ Vol 31:187-192.

xxx. Hegge, M., and Larson, V. (2008). Stressors and coping strategies of students in accelerated baccalaureate nursing programs. Nurse Educator, Vol 33(1), 26-30.

xxxi. Jimenez, C., Navia-Osorio, P., and Diaz, C. (2010). Stress and health in novice and experienced nursing students. Journal of Advanced Nursing, Vol 66(2), 442-455.

xxxii. Karademas, E., Karamvakalis, N., \& Zarogiannos, A. (2009). Life context and the experience of chronic illness: is the stress of life associated with illness perceptions and coping? Stress \& Health: Journal of the International Society for the Investigation of Stress, Vol 25(5), 405-412.

xxxiii. Landy, F.J., and Conte, J. (2007). Work in the 21st Century: An Introduction to Industrial and Organizational Psychology. Oxford: Blackwell Publishing Company.

xxxiv. Lazarus, R.S., and Cohen, J.B. (2007). Environmental Stress. (8 $8^{\text {th }}$ eds.).

xxxv. Lazarus, R.S., and Folkman, S. (2008). Stress, Appraisal, and Coping. 
xxxvi. Lenburg, E. A. (2008). Stress in the Lives of College Women: "Lots to Do and Not Much Time" Journal of Adolescent Research; Vol 21(6), 579-606.

xxxvii. Lewis, S.L., and Shaw, C.A. (2007). Stress and stress management.

xxxviii. Macan, G. (2016). Stress and coping: First-year Nepalese nursing students in clinical settings. Journal of Nursing Education: Vol 35(4) :163-169.

xxxix. Misra, R., and McKean, M. (2010). College Students' Academic Stress and its Relation to their anxiety, time management, and leisure Satisfaction, 16(1), 41-51

xl. Nancy, R.K. (2011). Stress and Coping Strategies among Nursing Students. Nursing and Midwifery Research Journal, $7(4)$

xli. Passer, M.W., and Smith, R.E. (2007). Psychology: The Science of the Mind and Behavior (3rd edition) McGraw-Hill

xlii. Peplau, H.(2015). A working definition of anxiety. American Journal of Nursing Science, 45-50, 49

xliii. Pestonjee, D.M.(2012). "Stress and Coping", Sage publication, pp. 15-21

xliv. Polychronopoulou, A. and Divaris, K. (2015). Perceived Sources of Stress among Greek Dental Students, 69 (6), 687 692.

xlv. Richardson, C., and Poole, H. (2011). Chronic pain and coping: A proposed role for nurses and nursing models. Journal of Advanced Nursing; 34 (1), 659-667.

xlvi. Roy, C. (2009). The Roy's Adaptation Model. (3rd ed.). Upper Saddle River: Pearson Education.

xlvii. Schafer, W. (2016). Passing the test of college stress. Stress management for wellness. 543-563.

xlviii. Sharif, F., and Masoumi, S. (2015). A qualitative study of nursing student experiences of clinical practice. BMC Nursing, $4(6), 1-7$.

xlix. Soares, M.H., and Oliveira, F.S. (2013). The relation between alcohol, tobacco and stress in nursing students, 9(2):8894.

1. Sreeramareddy, C.T. (2007). Psychological morbidity, sources of stress and coping strategies among undergraduate medical students of Nepal. BMC Medical Education.

li. Stevenson, A., and Harper, S. (2016). Workplace stress and the student learning experience, 14(2), 167-178.

lii. Timmins, F., and Kaliszer, M. (2012). Aspects of nurse education programmes that frequently cause stress to nursing students, 23(2), 203-211

liii. Watson, R., Deary, I., Thompson, D., and Li, G. (2008). A study of burnout in nursing students in Hong Kong: a questionnaire survey, International Journal of Nursing Studies, 1534-1542. 